Article

\title{
Inoculation with Mycorrhizal Fungi and Other Microbes to Improve the Morpho-Physiological and Floral Traits of Gazania rigens (L.) Gaertn
}

\author{
Ishan Saini ${ }^{1}$, Ashok Aggarwal ${ }^{1}$ and Prashant Kaushik ${ }^{2, *}$ \\ 1 Department of Botany, Kurukshetra University Kurukshetra, Kurukshetra 136119, India; \\ ishansaini121@gmail.com (I.S.); ashokbotanykuk@gmail.com (A.A.) \\ 2 Instituto de Conservación y Mejora de la Agrodiversidad Valenciana, Universitat Politècnica de València, \\ 46022 Valencia, Spain \\ * Correspondence: prakau@doctor.upv.es; Tel.: +34-963-877-000
}

Received: 14 January 2019; Accepted: 5 March 2019; Published: 8 March 2019

\begin{abstract}
In the present analysis, we evaluated the effect of different microbial inoculants on growth and floral responses of Gazania rigens (L.) Gaertn. Two prevailing arbuscular mycorrhizal fungi (AMF) i.e., Funelliformis mosseae and Acaulospora laevis, along with Trichoderma viride and Pseudomonas fluorescens, were examined in a pot experiment. Independent roles of these four microbes and their different combinations were used in sixteen treatments of G. rigens. The experiment was conducted in a polyhouse with five replicates per treatment in a randomized complete block design. The results of microbial inoculants were very effective for growth yield and flowering response over the control. Early flowering was noted in the combination of $F$. mosseae, A. laevis and P. fluorescens, which also showed the best results for flower head size, flower fresh and dry weight, total chlorophyll, carotene and phosphorus content. Arbuscular mycorrhiza (AM) root colonization (\%) and AM spore number were also the highest for the same treatment, whereas the number of leaves, number of buds and root length were maximum in the combined treatment (F. mosseae + A. laevis $+T$. viride $+P$. fluorescens). Overall, this study proposes that growers should consider microbial inoculants for the better yield and flower quality of G. rigens.
\end{abstract}

Keywords: arbuscular mycorrhizal fungi (AMF); Pseudomonas fluorescens; Trichoderma viride; microbes; bioinoculants; flower yield

\section{Introduction}

Gazania rigens (L.) Gaertn. (Family: Asteraceae) is an important annual flowering plant, commonly used as an ornamental garden plant [1]. Gazania has a long flowering duration from late spring to early summer [2]. The genus Gazania was named by Gaertner, honouring Theodorus Gaza, a 15th-century Italian scholar. Gazania along with other flowers, namely, Geranium, Pelargonium, Watsonia and Clivia were taken to Europe for cultivation from South Africa and from Europe, were subsequently used and popularized for the global horticultural trade [3]. G. rigens is one of the most common flowers on the market today, not only for ornamental purposes but also for its economic and medicinal importance $[4,5]$ especially for antimicrobial activity of bioactive compounds present in the plant tissues [6]. The global floriculture industry is growing at a rapid pace, and recently, a great deal of significance has been given to the floriculture industry in India because of its foreign exchange earning potential, guaranteeing a higher rate of profits for rural individuals, and encouraging global trade [7].

A high demand for any ornamental plant is a major concern, especially under harsh urban conditions, which demand plants with high tolerance to various environmental stresses [8]. According to NHB (National Horticulture Board, India), the area under floral cultivation increased to about 
248.51 thousand hectares in 2016-2017 while production of flowers is estimated around 1658 thousand tons of loose flowers and 472 thousand tons of cut flowers [9]. Therefore, to meet this high requirement, there should be some eco-friendly, low cost and sustainable strategy for intensive production and improvement of $G$. rigens cultivation. One of the methods is the use of bioinoculants, which are very beneficial, promising and favourable for soil [10-12].

Biofertilizers like beneficial fungi and certain phosphate-solubilizing bacteria (PSB), e.g., Pseudomonas fluorescens, are important for flower crop improvement [13]. Moreover, soil microbes from nutrient-poor ecosystems are known to form an important symbiosis with widely distributed plants to acquire essential macro and micronutrients [14]. Mycorrhizal association occurs between fungi and the roots of higher plants, and it has been acknowledged that arbuscular mycorrhizal fungi (AMF) provide phosphorus and other nutrients to plants [15]. The AMF approach ameliorates plant growth and can be an alternative to chemical fertilizers. Similarly, phosphorus-solubilizing bacteria have the ability to solubilize organic as well as inorganic phosphorus compounds by releasing organic acids or phosphatase enzymes [16,17]. Many studies have shown that the application of PSB has a synergistic effect when combined with AMF, as mycorrhizal exudates directly influence bacterial communities, enhancing water absorption of host plants [18-20].

Pseudomonas fluorescens, an aerobic multi-flagellated rod-shaped gram-negative plant growth-promoting rhizobacterium, plays a major role in plant growth development and in biological control of a wide range of pathogens [21]. It has been shown that $P$. fluorescens protects plant roots from the parasitic attack of Fusarium sp. and Pythium sp. [22-24]. Furthermore, P. fluorescens also produces many secondary metabolites that can act as a biocontrol agent for many fungal pathogens [25]. Similarly, plant roots secrete several ions, enzymes, free oxygen mucilage plus a diverse array of carbon-containing primary and secondary metabolites (organic acids, lipids, amino acids, flavonoids, sugars, aliphatic and aromatic compounds) that provide signals for root colonization [26]. Trichoderma viride, a non-mycorrhizal opportunistic, avirulent, free-living symbiont with phytostimulating activity, is widely used in floriculture practices for better plant growth $[27,28]$. T. viride enables root colonization, thereby enhancing plant root growth and metabolism by stimulating nutrient uptake. This can solve the problem of soil salinity, nutrition and drought [29]. Overall, these rhizospheric microbes bring considerable changes to plant metabolism and proteomes. These strategies are now being used at the nursery level for producing a better plant ideotype [30-32].

Biofertilizers like AMF, Pseudomonas, and Trichoderma can be an alternative source for enriching soil fertility and improving crop production [33]. It has been experimentally proven that AMF improves $\mathrm{P}$ and $\mathrm{N}$ uptake and other nutrients in plants [34]. Moreover, these microbes increase the mineralization and desorption of $\mathrm{P}$ from sparsely distributed sources and improve the internal $\mathrm{P}$ acquisition efficiency by lowering the $P$ demand of plant growth [35]. Furthermore, these below-ground microbes govern the above-ground biodiversity, modifying the unfavourable environment to stimulate soil nutrient cycling [36]. AMF, being the most important biofertilizer, found in almost $90 \%$ of vascularophytes, are ubiquitous obligate symbionts in which fungal partners help the host by increasing the absorption of water and nutrients, and on the other hand, host plants act as a carbon source for the fungi [37].

Recently, it was concluded that combined effects of bioinoculants increase soil production, which ultimately lead to better growth of plants [38]. Earlier work on other ornamental species, namely, Zinnia elegans, Tagetes patula and Salvia splendens, showed progressive effects of AMF on growth and overall yield $[17,39]$. Therefore, we planned our study to scrutinize the effectiveness of AMF alone and in combination with T. viride and P. fluorescens, as no work has been done on G. rigens using these bioinoculants as biofertilizers in pot culture cultivation.

\section{Materials and Methods}

\subsection{Soil Preparation}

A pot experiment was conducted in a polyhouse of the Department of Botany, Kurukshetra University Kurukshetra, Haryana, India at $23 \pm 5{ }^{\circ} \mathrm{C}$ and $45-65 \%$ relative humidity. A mixture of soil 
and sand (3:1) was used for the experiment, with $64.2 \%$ sand, $21.8 \%$ silt, $3.9 \%$ clay, $0.042 \% \mathrm{~N}, 0.017 \%$ available $\mathrm{P}, 0.06 \%$ organic carbon and $\mathrm{pH} 7.4 \pm 0$ and was sieved through a 2-mm sieve and autoclaved (twice) at $121^{\circ} \mathrm{C}$ to eradicate microorganisms.

\subsection{Experimental Setup}

\subsubsection{AMF Inoculum Preparedness and Multiplication}

Spores of the selected AMF (Funelliformis mosseae and Acaulospora laevis Gerd. \& Trappe) were isolated from the rhizosphere of G. rigens plants growing in the botanical garden of Kurukshetra University, Kurukshetra, and identified using a key defined elsewhere [40]. Firstly, starter inoculum was prepared for both types of spores using a funnel technique [17], and then this starter inoculum was multiplied in standard pot culture using barley (Hordeum vulgare) as a host for 90 days because barley has a fibrous root system and short life span with the matching crop season to mass multiply the AMF inoculum.

\subsubsection{Inoculum Preparation of Trichoderma viride Pers.}

Inoculum preparation of $T$. viride was done by the soil dilution plate method [41] on potato dextrose agar medium and was identified based on a manual [42]. The cultures plates were incubated at $30{ }^{\circ} \mathrm{C}$ for 4 days. Then, the inoculum was multiplied using wheat-bran, saw-dust and water in a ratio of 3:1:1.

\subsubsection{Inoculum Preparation of Pseudomonas fluorescens (MTCC No. 103)}

Inoculum preparation of $P$. fluorescens was performed on nutrient broth medium prepared in sterilized water (incubated at $32{ }^{\circ} \mathrm{C}$ for $48 \mathrm{~h}$ ). A culture of $P$. fluorescens was procured from the Institute of Microbial Technology (IMTECH, Chandigarh, India) and a concentration of $1 \times 10^{9}$ colony $\mathrm{mL}^{-1}$ was obtained and used for the inoculation.

\subsection{Experimental Design}

The experiment was laid out in a complete randomized block design with five replicates of each treatment including a control. Earthenware pots of $2 \mathrm{~kg}$ capacity were filled with sterilized soil: sand. AMF treatment containing 10\% (w/w of soil) of the selected AMF inoculum having 645-685 AMF spores was added along with chopped AMF colonized root pieces of barley having an infection level of 80-85 percent. For T. viride infection, inoculum with a density of $3.4 \times 10^{8} \mathrm{CFU} \mathrm{g}^{-1}$ was added; $\mathrm{CFU} / \mathrm{g}$ (colony-forming units per gram) for solids were determined using the formula $\mathrm{CFU} / \mathrm{g}=$ (no. of colonies $\times$ dilution factor)/weight of the culture plate. P. fluorescens treatment involved the dipping of roots of 10-day-old plantlets of G. rigens for 5-10 $\mathrm{min}$. Two plantlets were transplanted into each pot and were regularly watered. Hoagland's solution (without $\mathrm{KH}_{2} \mathrm{PO}_{4}$ ) was also provided at 14-day intervals. The list of a total of sixteen different treatment combinations is represented in Table 1.

Table 1. The following sixteen treatments $(\mathrm{Tt})$ were maintained for the growth experiment.

\begin{tabular}{ll}
\hline Treatment & Constituents \\
\hline$T t_{1}$ & Control (without any bio-inoculants) \\
$T t_{2}$ & Funelliformis mosseae $(\mathrm{F})$ \\
$T t_{3}$ & Acaulospora laevis $(\mathrm{A})$ \\
$T t_{4}$ & Trichoderma viride $(\mathrm{T})$ \\
$T t_{5}$ & Pseudomonas fluorescens $(\mathrm{P})$ \\
$T t_{6}$ & F. mosseae + A. laevis $(\mathrm{F}+\mathrm{A})$ \\
$T t_{7}$ & F. mosseae + T. viride $(\mathrm{F}+\mathrm{T})$ \\
$T t_{8}$ & F. mosseae + P. fluorescens $(\mathrm{F}+\mathrm{P})$ \\
$T t_{9}$ & A. laevis + T. viride $(\mathrm{A}+\mathrm{T})$ \\
$T t_{10}$ & A. laevis + P. fluorescens $(\mathrm{A}+\mathrm{P})$ \\
\hline
\end{tabular}


Table 1. Cont.

\begin{tabular}{ll}
\hline Treatment & Constituents \\
\hline$T t_{11}$ & T. viride + P. fluorescens $(\mathrm{T}+\mathrm{P})$ \\
$T t_{12}$ & F. mosseae + A. laevis + T. viride $(F+A+T)$ \\
$T t_{13}$ & F. mosseae + A. laevis + P. fluorescens $(\mathrm{F}+\mathrm{A}+\mathrm{P})$ \\
$T t_{14}$ & F. mosseae $+T$. viride + P. fluorescens $(\mathrm{F}+\mathrm{T}+\mathrm{P})$ \\
$T t_{15}$ & A. laevis $+T$. viride $+P$. fluorescens $(\mathrm{A}+\mathrm{T}+\mathrm{P})$ \\
$T t_{16}$ & F. mosseae + A. laevis + T. viride + P. fluorescens $(\mathrm{F}+\mathrm{A}+\mathrm{T}+\mathrm{P})$, consortium \\
\hline
\end{tabular}

\subsection{Characterization and Statistical Analysis}

Plants were harvested after 90 days, and the length of the root, peduncle, and diameter of the floral head were measured. The fresh and dry weights of the shoot, root and floral head were weighed separately. Leaf area was measured by using a leaf area meter (Systronics 211, Ahmedabad, India). Numbers of leaves and floral heads were counted per plant per treatment. During the course of the experiment, the life-span of each floral head was recorded per plant per treatment. Chlorophyll and carotenoid contents were determined by Arnon's method [43]; briefly, $0.1 \mathrm{~g}$ of fresh leaf samples was crushed with $80 \%$ acetone using a mortar and pestle. The homogenate obtained was then centrifuged at $2000 \mathrm{rpm}$ for about 15-20 min. The supernatant was collected, and absorbance was determined using a UV-Vis. spectrophotometer (Specord- 205 Analytik Jena AG, Jena, Germany) at $645 \mathrm{~nm}$ and $663 \mathrm{~nm}$ for chlorophyll a and chlorophyll b, respectively, and at $520 \mathrm{~nm}$ for carotenoids using $80 \%$ acetone as a blank.

The anthocyanin content in the florets was measured using Tsushida and Suzuki's method [44]; briefly, methanol with $1 \%$ hydrochloric acid was used. Thereafter, the absorbance-based anthocyanin concentration was determined at $530 \mathrm{~nm}$ using a UV-Vis. spectrophotometer (Specord- 205 Analytik Jena AG, Jena, Germany).

Acid and alkaline phosphatase activities were determined by Tabatabai and Bremner's method [45]; briefly, $1 \mathrm{~g}$ of washed roots was homogenized in ice-cold sodium acetate buffer $(0.1 \mathrm{M}$ with $\mathrm{pH} 4.8)$ for acidic phosphatase activity, and sodium bicarbonate buffer $(0.05 \mathrm{~N}$ with $\mathrm{pH} 10)$ was used for the estimation of the alkaline phosphatase activity. After centrifugation at 10,000 rpm for $15 \mathrm{~min}$, the supernatant was used for assaying phosphatase activity. Root and shoot phosphorus contents in the samples were analyzed by the vanadomolybdo phosphoric yellow colour method [46]. AMF spores were extracted from the rhizospheric soil of gazania plants using wet sieving and a decanting technique [47] and then counted by the gridline intersect method [48]. AMF root colonization was done using $0.01 \%$ trypan blue stain after cleaning the root pieces with $10 \% \mathrm{KOH} \mathrm{[49],} \mathrm{and} \mathrm{the} \mathrm{quantification} \mathrm{of} \mathrm{colonized}$ roots was completed using the root slide technique [50]. AM Root Colonization (\%) was determined based on the formula $100 \times$ (number of root segments colonized/total number of root segments).

Means of each treatment were subjected to analysis of variance (ANOVA) to determine differences among the sixteen treatments. The significance of differences among treatment means was evaluated using Duncan's multiple range test (DMRT) for comparison of variance separated with (least significant difference) (LSD) as a post hoc test through SPSS software (11.5 version) [51].

\section{Results}

Highly significant differences $(p<0.001)$ were present in the mean values of the groups that constituted the sixteen different treatments applied to the gazania plants (Table 2). The application of bioinoculants showed a significant and positive effect on the morpho-physiological as well as phytochemical traits of the Gazania rigens (L.) Gaertn (Table 2). The effect of bioinoculants on several morphological parameters of G. rigens was statistically significant (Table 2. Both shoot and root weight were maximum in $\mathrm{Tt}_{13}, \mathrm{~F}+\mathrm{A}+\mathrm{P}$ as depicted in Table 2 . The longest root length was noted in $\mathrm{Tt}_{16}$, $\mathrm{F}+\mathrm{A}+\mathrm{T}+$ P i.e., combined treatment $(7.27 \pm 0.2)$ followed by $\mathrm{Tt}_{13}(7.12 \pm 0.19)$. The highest number of leaves were found in $\mathrm{Tt}_{16}(61 \pm 2.23)$ followed by $\mathrm{Tt}_{13}(52 \pm 5.24)$, while for leaf area, the $\mathrm{Tt}_{13}$ treatment $(21.2 \pm 0.24)$ showed the best result followed by $\mathrm{Tt}_{6}, \mathrm{~F}+\mathrm{A}(20.74 \pm 0.43)$ (Table 2). 
From Table 2, it is clear that AMF root colonization and AMF spore number followed the same trend, where $\mathrm{Tt}_{13}$ (spore number, $127 \pm 8.7$; root colonization $75 \pm 4.6$ ) proved to be the best treatment followed by $\mathrm{Tt}_{16}$ (spore number, $121 \pm 8.9$; root colonization $68 \pm 8.8$ ) (Table 2). Plants inoculated with bioinoculants showed significant flowering as compared to un-inoculated controls (Table 3). Plant inoculated with $\mathrm{F}+\mathrm{A}+\mathrm{P}$ bloomed first whereas un-inoculated plants took 17 days longer after all the inoculated plants flowered. The inoculated plants not only flowered first but also had a significantly higher number of flowers. $\mathrm{Tt}_{16}(\mathrm{~F}+\mathrm{A}+\mathrm{T}+\mathrm{P})$, i.e., consortium, showed the highest number of flowers $(11 \pm 1.58)$ (Table 3). The peduncle length among inoculated plants was longest in $\mathrm{Tt}_{13}(\mathrm{~F}+\mathrm{A}+\mathrm{P})$ (Table 3). The diameter and weight of the floral head also showed the same trend, being the heaviest in $\mathrm{Tt}_{13}$ followed by the consortium (Table 3).

The differences among the AM root colonization (\%) are displayed in Figure 1. Four treatments comprising the control, Pseudomonas fluorescence, Trichoderma viride and both together did not have any AM root colonization, whereas, the highest value, i.e., above $80 \%$ of the root, was observed in the FAP treatment (Figure 1).

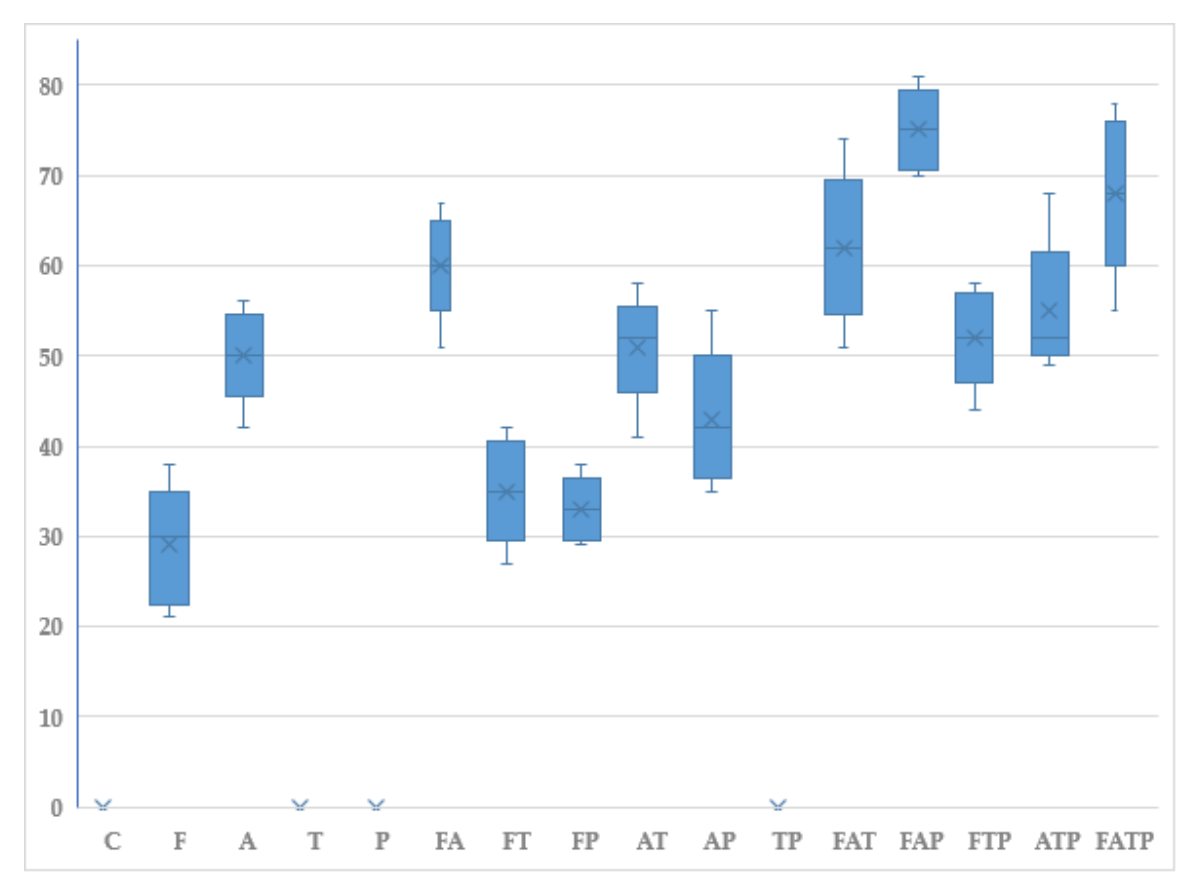

Figure 1. AM root colonization (\%) in the sixteen treatments. C-Control, F-Funelliformis mosseae, A-Acaulospora laevis, T-Trichoderma viride, and $\mathrm{P}-$ Pseudomonas fluorescence.

Further, in the case of total chlorophyll, carotenoid and anthocyanin contents, as depicted in Table 4, $\mathrm{Tt}_{13}(\mathrm{~F}+\mathrm{A}+\mathrm{P})$ showed the best result as compared to other treatments, with the lowest values in the control. Total chlorophyll (chl) and carotenoid contents were maximum in the $\mathrm{F}+\mathrm{A}+\mathrm{P}$ treatment (chlorophyll-a, $1.108 \pm 0.168$; chlorophyll-b, $0.777 \pm 0.118$; carotenoid, $0.123 \pm 0.027$ ) (Table 4). The floral anthocyanin content was highest under the combined effect of $\mathrm{F}+\mathrm{A}+\mathrm{P}, \mathrm{Tt}_{13}(35.47 \pm 0.815)$ as shown in Table 4, followed by the consortium treatment, $\mathrm{Tt}_{16}(34.95 \pm 0.851)$. Similarly, all the biochemical parameters illustrated in Table 3 showed a better result in the treated plants as compared to the control. The total phosphorus content was highest in the $\mathrm{Tt}_{13}(\mathrm{~F}+\mathrm{A}+\mathrm{P}$ ) (shoot phosphorus, $1.313 \pm 0.078$; root phosphorus, $1.56 \pm 0.125$ ) followed by the consortium treatment, $\mathrm{Tt}_{16}$ (shoot phosphorus, $1.215 \pm$ 0.256; root phosphorus, $1.397 \pm 0.316$ ) (Table 4). Compared to enhanced phosphatase activity, identical results were shown in the $\mathrm{Tt}_{13}$ treatment (acidic phosphatase, $1.565 \pm 0.196$; alkaline phosphatase, $2.531 \pm 0.204$ ) followed by the consortium treatment (acidic phosphatase, $1.502 \pm 0.209$; alkaline phosphatase, $2.314 \pm 0.114$ ) as shown in Table 4 . 
Table 2. Effect of bioinoculants on morphological parameters of Gazania rigens.

\begin{tabular}{|c|c|c|c|c|c|c|c|c|c|}
\hline Treatments & $\begin{array}{l}\text { Fresh Shoot } \\
\text { Weight (g) }\end{array}$ & $\begin{array}{l}\text { Dry Shoot } \\
\text { Weight (g) }\end{array}$ & $\begin{array}{l}\text { Fresh Root } \\
\text { Weight (g) }\end{array}$ & $\begin{array}{l}\text { Dry Root } \\
\text { Weight (g) }\end{array}$ & $\begin{array}{l}\text { Root Length } \\
\text { (cm) }\end{array}$ & $\begin{array}{c}\text { Number of } \\
\text { Leaves }\end{array}$ & $\begin{array}{l}\text { Leaf Area } \\
\left(\mathrm{cm}^{2}\right)\end{array}$ & $\begin{array}{l}\text { AM Spore } \\
\text { Number }\end{array}$ & $\begin{array}{c}\text { AM Root } \\
\text { Colonization }(\%)\end{array}$ \\
\hline Control & $6.01 \pm 1.09^{\mathrm{k} \ddagger}$ & $1.069 \pm 0.12^{k}$ & $1.8 \pm 0.34^{\mathrm{j}}$ & $0.3 \pm 0.05^{k}$ & $1.97 \pm 0.36^{\mathrm{i}}$ & $9 \pm 2.23^{1}$ & $8.3 \pm 0.61^{k}$ & $0 \pm 0^{g}$ & $0 \pm 0^{g}$ \\
\hline Funelliformis mosseae $(\mathrm{F}) \dagger$ & $20.3 \pm 1.88$ hi & $15.26 \pm 0.83^{h}$ & $2.76 \pm 0.19^{g}$ & $0.89 \pm 0.05^{h}$ & $4.9 \pm 0.26^{\mathrm{e}}$ & $18 \pm 3.08^{j}$ & $14.5 \pm 0.42^{\mathrm{f}}$ & $50 \pm 8.2^{\mathrm{f}}$ & $29 \pm 6.7^{f}$ \\
\hline Acaulospora laevis (A) & $21.12 \pm 2.04^{\mathrm{h}}$ & $15.921 \pm 1.31^{\mathrm{h}}$ & $2.54 \pm 0.15 \mathrm{gh}$ & $0.65 \pm 0.08^{\mathrm{i}}$ & $5.8 \pm 0.22^{\mathrm{cd}}$ & $29 \pm 3.16^{\mathrm{hi}}$ & $14.8 \pm 0.36^{\mathrm{f}}$ & $57 \pm 4.6^{\mathrm{f}}$ & $50 \pm 5.2$ de \\
\hline Trichoderma viride $(\mathrm{T})$ & $15.51 \pm 2.45^{\mathrm{j}}$ & $11.63 \pm 0.85^{j}$ & $2.2 \pm 0.18^{\mathrm{i}}$ & $0.42 \pm 0.02^{j}$ & $3.1 \pm 0.35^{h}$ & $13 \pm 1.22^{\mathrm{k}}$ & $12.5 \pm 0.34^{j}$ & $0 \pm 0 \mathrm{~g}$ & $0 \pm 0 \mathrm{~g}$ \\
\hline Pseudomonas fluorescence (P) & $18.53 \pm 1.71^{\mathrm{i}}$ & $13.36 \pm 0.55^{\mathrm{i}}$ & $2.3 \pm 0.17^{\mathrm{h}}$ & $0.48 \pm 0.02^{\mathrm{ij}}$ & $3.4 \pm 0.25 \mathrm{gh}$ & $15 \pm 1.58^{\mathrm{jk}}$ & $13.7 \pm 0.21^{\mathrm{h}}$ & $0 \pm 0 \mathrm{~g}$ & $0 \pm 0 \mathrm{~g}$ \\
\hline FA & $36.65 \pm 1.35^{b}$ & $32.17 \pm 0.89^{a}$ & $2.8 \pm 0.16^{g}$ & $1.03 \pm 0.11 \mathrm{gh}$ & $7 \pm 0.36^{\mathrm{ab}}$ & $30 \pm 3.39 \mathrm{hi}$ & $20.74 \pm 0.43^{a}$ & $91 \pm 8.4^{\mathrm{c}}$ & $60 \pm 5.9^{c}$ \\
\hline FT & $32.73 \pm 1.3^{c}$ & $26.85 \pm 0.59^{c}$ & $3.5 \pm 0.26^{\mathrm{f}}$ & $2.05 \pm 0.36^{\mathrm{e}}$ & $4.11 \pm 0.36^{\mathrm{f}}$ & $32 \pm 3.16^{\mathrm{gh}}$ & $16.28 \pm 0.19^{d}$ & $76 \pm 6.6^{\mathrm{de}}$ & $35 \pm 5.8^{\mathrm{f}}$ \\
\hline FP & $31.11 \pm 1.63^{\mathrm{cd}}$ & $23.69 \pm 0.66^{\mathrm{d}}$ & $4.83 \pm 0.16^{\mathrm{c}}$ & $2.98 \pm 0.27^{c}$ & $3.7 \pm 0.38^{\mathrm{fg}}$ & $33 \pm 3.8^{\mathrm{fgh}}$ & $18.3 \pm 0.35^{b}$ & $70 \pm 7.3^{j}$ & $33 \pm 3.6^{f}$ \\
\hline AT & $30.08 \pm 1.47^{\mathrm{de}}$ & $22.55 \pm 0.62^{\mathrm{e}}$ & $4.39 \pm 0.29^{d}$ & $2.54 \pm 0.12^{\mathrm{d}}$ & $5.6 \pm 0.45^{\mathrm{de}}$ & $35 \pm 4.12^{\text {efg }}$ & $13.9 \pm 0.46^{\mathrm{h}}$ & $85 \pm 8^{c d}$ & $51 \pm 6.2^{\mathrm{d}}$ \\
\hline $\mathrm{AP}$ & $35.27 \pm 2.6^{b}$ & $30.06 \pm 0.86^{b}$ & $5.83 \pm 0.16^{\mathrm{b}}$ & $3.86 \pm 0.16^{b}$ & $4.8 \pm 0.48^{\mathrm{e}}$ & $38 \pm 2.91$ de & $15.5 \pm 0.26^{\mathrm{e}}$ & $78 \pm 8.9$ de & $43 \pm 7.7^{\mathrm{e}}$ \\
\hline $\mathrm{TP}$ & $22.72 \pm 2.39^{h}$ & $17.06 \pm 0.59 \mathrm{~g}$ & $4.01 \pm 0.25^{\mathrm{de}}$ & $2.15 \pm 0.14^{\mathrm{e}}$ & $3.5 \pm 0.1 \mathrm{gh}$ & $27 \pm 4.3^{\mathrm{i}}$ & $14 \pm 0.13 \mathrm{~g}$ & $0 \pm 0 \mathrm{~g}$ & $0 \pm 0 \mathrm{~g}$ \\
\hline FAT & $25.7 \pm 2.13 \mathrm{~g}$ & $20.55 \pm 0.44^{\mathrm{f}}$ & $2.9 \pm 0.08 \mathrm{~g}$ & $1.05 \pm 0.13 \mathrm{gh}$ & $6.67 \pm 0.23^{b}$ & $41 \pm 4^{\mathrm{cd}}$ & $13 \pm 0.36^{\mathrm{i}}$ & $113 \pm 11.5^{b}$ & $62 \pm 8.5^{\mathrm{bc}}$ \\
\hline FAP & $39.84 \pm 2.75^{\mathrm{a}}$ & $32.64 \pm 0.74^{a}$ & $6.5 \pm 0.15^{\mathrm{a}}$ & $4.5 \pm 0.24^{\mathrm{a}}$ & $7.12 \pm 0.19^{a}$ & $52 \pm 5.24^{b}$ & $21.2 \pm 0.24^{a}$ & $127 \pm 8.7^{\mathrm{a}}$ & $75 \pm 4.6^{\mathrm{a}}$ \\
\hline FTP & $27.42 \pm 1.62 \mathrm{fg}$ & $21.21 \pm 0.94^{\mathrm{f}}$ & $3.93 \pm 0.23^{\mathrm{e}}$ & $1.25 \pm 0.08 \mathrm{~g}$ & $6.1 \pm 0.5^{c}$ & $37 \pm 3.67$ def & $16.6 \pm 0.39 \mathrm{~d}$ & $89 \pm 10.5^{c}$ & $52 \pm 5.4^{\mathrm{d}}$ \\
\hline ATP & $27.98 \pm 1.39$ efg & $22.71 \pm 0.67^{\mathrm{e}}$ & $3.63 \pm 0.11^{e f}$ & $1.76 \pm 0.11^{\mathrm{f}}$ & $5.2 \pm 0.35^{\mathrm{g}}$ & $45 \pm 1.58^{c}$ & $14.5 \pm 0.29^{\mathrm{f}}$ & $95 \pm 10.6^{c}$ & $55 \pm 7.5^{\mathrm{cd}}$ \\
\hline FATP & $28.82 \pm 1.89 \mathrm{def}$ & $22.58 \pm 0.43^{\mathrm{e}}$ & $5.82 \pm 0.13^{b}$ & $3.8 \pm 0.25^{b}$ & $7.27 \pm 0.2^{\mathrm{a}}$ & $61 \pm 2.23^{a}$ & $17.17 \pm 0.48^{\mathrm{c}}$ & $121 \pm 8.9^{a b}$ & $68 \pm 8.8^{a b}$ \\
\hline F-ratio & 101.639 & 605.75 & 104.491 & 315.15 & 112.983 & 91.697 & 359.306 & 104.293 & 170.635 \\
\hline Probability & $<0.001$ & $<0.001$ & $<0.001$ & $<0.001$ & $<0.001$ & $<0.001$ & $<0.001$ & $<0.001$ & $<0.001$ \\
\hline
\end{tabular}

† F—Funelliformis mosseae, A—Acaulospora laevis, T—Trichoderma viride, $\mathrm{P} —$ Pseudomonas fluorescence; \pm —Standard deviation; FW—Fresh Weight, $\ddagger$ values in columns followed by the same letter are not significantly different, $p \leq 0.05$, LSD. 
Table 3. Effect of bioinoculants on floral parameters of Gazania rigens.

\begin{tabular}{|c|c|c|c|c|c|c|}
\hline Treatments & $\begin{array}{c}\text { No. of Floral } \\
\text { Heads Per Plant }\end{array}$ & $\begin{array}{c}\text { Peduncle Length } \\
(\mathrm{cm})\end{array}$ & $\begin{array}{c}\text { Diameter of Flower } \\
\text { Head }(\mathrm{cm})\end{array}$ & $\begin{array}{c}\text { Flower Fresh } \\
\text { Weight (g) }\end{array}$ & $\begin{array}{l}\text { Flower Dry } \\
\text { Weight (g) }\end{array}$ & $\begin{array}{c}\text { Flower Age on the } \\
\text { Plant (Days) }\end{array}$ \\
\hline Control & $2 \pm 0.707^{h \ddagger}$ & $1.88 \pm 0.609^{\mathrm{i}}$ & $2.7 \pm 0.46^{\mathrm{k}}$ & $2.46 \pm 0.079^{j}$ & $0.73 \pm 0.091^{j}$ & $2 \pm 0.7^{\mathrm{h}}$ \\
\hline Funelliformis mosseae $(\mathrm{F})+$ & $5 \pm 1.581$ ef & $4.5 \pm 0.412 \mathrm{de}$ & $7.51 \pm 0.71$ def & $3.4 \pm 0.064$ def & $1.68 \pm 0.088$ ef & $5 \pm 1.41$ efg \\
\hline Acaulospora laevis (A) & $6 \pm 0.707$ de & $4.2 \pm 0.291 \mathrm{fg}$ & $6.5 \pm 0.68$ ghi & $3.26 \pm 0.113 \mathrm{gh}$ & $1.53 \pm 0.041 \mathrm{gh}$ & $6 \pm 1^{\text {cde }}$ \\
\hline Trichoderma viride $(\mathrm{T})$ & $3 \pm 0.707 \mathrm{gh}$ & $3.04 \pm 0.304^{h}$ & $5.2 \pm 0.58^{j}$ & $3.1 \pm 0.112 \mathrm{hi}$ & $1.38 \pm 0.031^{\mathrm{i}}$ & $3 \pm 1.22 \mathrm{gh}$ \\
\hline Pseudomonas fluorescence (P) & $4 \pm 1.581 \mathrm{fg}$ & $3.62 \pm 0.319 g$ & $5.7 \pm 0.83^{\mathrm{ij}}$ & $3.62 \pm 0.055^{c}$ & $1.45 \pm 0.015^{\mathrm{hi}}$ & $4 \pm 2^{\text {fgh }}$ \\
\hline FA & $8 \pm 0.707^{a}$ & $6.1 \pm 0.337^{b}$ & $8 \pm 0.79$ cde & $3.7 \pm 0.067^{c}$ & $1.9 \pm 0.064^{\mathrm{d}}$ & $7 \pm 1.58^{\mathrm{bcd}}$ \\
\hline FT & $6 \pm 0.707 \mathrm{de}$ & $5.2 \pm 0.447^{c}$ & $8.5 \pm 0.71^{\mathrm{bcd}}$ & $3.34 \pm 0.14^{\mathrm{efg}}$ & $1.98 \pm 0.066^{\mathrm{d}}$ & $6 \pm 1.58^{\text {cde }}$ \\
\hline FP & $7 \pm 1.224^{\mathrm{cd}}$ & $4.8 \pm 0.524^{\text {cde }}$ & $7 \pm 0.61 \mathrm{fgh}$ & $3.5 \pm 0.113^{d}$ & $1.61 \pm 0.08^{\mathrm{fg}}$ & $6 \pm 1^{\text {cde }}$ \\
\hline $\mathrm{AT}$ & $7 \pm 0.707^{c d}$ & $4.3 \pm 0.339$ ef & $8.2 \pm 0.36^{\text {cde }}$ & $3.3 \pm 0.14 \mathrm{fg}$ & $1.77 \pm 0.05^{\mathrm{e}}$ & $7 \pm 1.73 \mathrm{bcd}$ \\
\hline $\mathrm{AP}$ & $8 \pm 1^{\mathrm{bc}}$ & $6.2 \pm 0.587^{b}$ & $6.1 \pm 0.22$ hij & $3.27 \pm 0.046^{\mathrm{gh}}$ & $1.57 \pm 0.09 \mathrm{~g}$ & $7 \pm 1.22 \mathrm{bcd}$ \\
\hline $\mathrm{TP}$ & $5 \pm 0.707$ ef & $6 \pm 0.474^{b}$ & $6 \pm 0.5^{\mathrm{ij}}$ & $4.07 \pm 0.04^{\mathrm{b}}$ & $1.55 \pm 0.146^{\mathrm{g}}$ & $5 \pm 0.7$ efg \\
\hline FAT & $7 \pm 1.224^{\mathrm{cd}}$ & $4.5 \pm 0.463^{\mathrm{de}}$ & $8.9 \pm 0.35^{\mathrm{abc}}$ & $4.32 \pm 0.041^{\mathrm{a}}$ & $2.2 \pm 0.015^{\mathrm{c}}$ & $9 \pm 1^{a b}$ \\
\hline FAP & $8 \pm 1.224^{b c}$ & $7.3 \pm 0.412^{\mathrm{a}}$ & $9.6 \pm 1.09^{\mathrm{a}}$ & $4.43 \pm 0.015^{\mathrm{a}}$ & $2.56 \pm 0.015^{\mathrm{a}}$ & $10 \pm 1.58^{\mathrm{a}}$ \\
\hline FTP & $8 \pm 0.707^{b c}$ & $4.7 \pm 0.158^{\text {cde }}$ & $8.1 \pm 0.54$ cde & $3.43 \pm 0.022 \mathrm{de}$ & $1.71 \pm 0.027^{\mathrm{e}}$ & $8 \pm 1.58^{a b c}$ \\
\hline ATP & $9 \pm 1.224^{b}$ & $5.01 \pm 0.312^{\mathrm{cd}}$ & $7.3 \pm 0.73$ efg & $3.41 \pm 0.051 \mathrm{def}$ & $1.69 \pm 0.015$ ef & $8 \pm 2^{a b c}$ \\
\hline FATP & $11 \pm 1.58^{\mathrm{a}}$ & $5.8 \pm 0.33^{\mathrm{b}}$ & $9.3 \pm 1.43^{\mathrm{ab}}$ & $4.16 \pm 0.027^{b}$ & $2.43 \pm 0.043^{b}$ & $10 \pm 2.54^{\mathrm{a}}$ \\
\hline F-ratio & 20.813 & 46.529 & 29.819 & 152.091 & 194.08 & 11.68 \\
\hline Probability & $<0.001$ & $<0.001$ & $<0.001$ & $<0.001$ & $<0.001$ & $<0.001$ \\
\hline
\end{tabular}

† F-Funelliformis mosseae, A—Acaulospora laevis, T—Trichoderma viride, $\mathrm{P} —$ Pseudomonas fluorescence; \pm -Standard deviation; FW—Fresh Weight, $\ddagger$ values in a column followed by the same letter are not significantly different, $p \leq 0.05$, LSD 
Table 4. Effect of bioinoculants on biochemical aspects of Gazania rigens.

\begin{tabular}{|c|c|c|c|c|c|c|c|c|c|}
\hline Treatments & $\begin{array}{c}\text { Chlorophyll a } \\
\text { (mg/g FW) }\end{array}$ & $\begin{array}{l}\text { Chlorophyll b } \\
\text { (mg/g FW) }\end{array}$ & $\begin{array}{c}\text { Total } \\
\text { Chlorophyll } \\
\text { (mg/g FW) }\end{array}$ & $\begin{array}{c}\text { Total } \\
\text { Carotenoids } \\
\text { (mg/g FW) }\end{array}$ & $\begin{array}{l}\text { Shoot Phosphorus } \\
\text { Content }(\%)\end{array}$ & $\begin{array}{c}\text { Root Phosphorus } \\
\text { Content (\%) }\end{array}$ & $\begin{array}{c}\text { Acidic } \\
\text { Phosphatase (IU } \\
\left.\mathrm{g}^{-1} \mathrm{FW}\right)\end{array}$ & $\begin{array}{c}\text { Alkaline } \\
\text { Phosphatase (IU } \\
\mathrm{g}^{-1} \text { FW) }\end{array}$ & $\begin{array}{c}\text { Anthocyanin } \\
\text { Content } \\
\text { (mg/100 g FW) }\end{array}$ \\
\hline Control & $0.233 \pm 0.08^{g}$ & $0.121 \pm 0.036^{\mathrm{g}}$ & $0.354 \pm 0.075^{1}$ & $0.012 \pm 0.004^{k}$ & $0.321 \pm 0.105^{\mathrm{i}}$ & $0.395 \pm 0.088^{h}$ & $0.6 \pm 0.019^{\mathrm{h}}$ & $1.411 \pm 0.14^{\mathrm{i}}$ & $17.4 \pm 1.398^{\mathrm{i}}$ \\
\hline Funelliformis mosseae $(\mathrm{F}) \dagger$ & $0.59 \pm 0.11$ def & $0.402 \pm 0.112^{\text {ef }}$ & $0.992 \pm 0.152^{\mathrm{ij}}$ & $0.037 \pm 0.014^{\mathrm{ijk}}$ & $0.777 \pm 0.18^{\text {efgh }}$ & $0.845 \pm 0.119$ efg & $0.925 \pm 0.121$ efg & $1.777 \pm 0.109 \mathrm{gh}$ & $26.3 \pm 0.988^{\mathrm{e}}$ \\
\hline Acaulospora laevis (A) & $0.615 \pm 0.153 \mathrm{de}$ & $0.417 \pm 0.11$ ef & $1.032 \pm 0.259$ hi & $0.049 \pm 0.011$ ghi & $0.7 \pm 0.235$ fgh & $0.843 \pm 0.139$ efg & $1.003 \pm 0.134$ defg & $1.875 \pm 0.088^{\text {efg }}$ & $28.3 \pm 0.948^{\mathrm{d}}$ \\
\hline Trichoderma viride $(\mathrm{T})$ & $0.4 \pm 0.068$ efg & $0.201 \pm 0.038^{\mathrm{fg}}$ & $0.601 \pm 0.087^{k}$ & $0.02 \pm 0.009^{\mathrm{jk}}$ & $0.538 \pm 0.123 \mathrm{gh}$ & $0.611 \pm 0.125 \mathrm{gh}$ & $0.789 \pm 0.12 \mathrm{gh}$ & $1.656 \pm 0.083^{\mathrm{h}}$ & $20.8 \pm 0.923^{h}$ \\
\hline Pseudomonas fluorescence (P) & $0.387 \pm 0.087^{\mathrm{fg}}$ & $0.32 \pm 0.108^{\mathrm{fg}}$ & $0.707 \pm 0.071^{\mathrm{jk}}$ & $0.025 \pm 0.004^{\mathrm{ijk}}$ & $0.601 \pm 0.139$ fgh & $0.695 \pm 0.218^{\mathrm{fg}}$ & $0.802 \pm 0.132 \mathrm{fg}$ & $1.687 \pm 0.113 \mathrm{gh}$ & $21.11 \pm 0.998^{\mathrm{f}}$ \\
\hline FA & $0.702 \pm 0.137^{\mathrm{cd}}$ & $0.489 \pm 0.173^{\mathrm{def}}$ & $1.191 \pm 0.212^{\text {efgh }}$ & $0.087 \pm 0.019$ cde & $0.829 \pm 0.2^{\text {cdef }}$ & $0.892 \pm 0.13$ ef & $1.082 \pm 0.171^{\text {cde }}$ & $2.075 \pm 0.134^{\mathrm{cd}}$ & $32.23 \pm 0.619 \mathrm{bc}$ \\
\hline FT & $0.666 \pm 0.153^{\mathrm{cd}}$ & $0.432 \pm 0.137$ ef & $1.098 \pm 0.047 \mathrm{ghi}$ & $0.055 \pm 0.014$ fgh & $0.813 \pm 0.188^{\text {defgh }}$ & $0.885 \pm 0.167^{\text {ef }}$ & $0.987 \pm 0.184$ defg & $1.978 \pm 0.091$ def & $27.1 \pm 1.049^{\mathrm{e}}$ \\
\hline FP & $0.767 \pm 0.15^{\mathrm{bcd}}$ & $0.571 \pm 0.197$ abcde & $1.338 \pm 0.295^{\text {defg }}$ & $0.062 \pm 0.017^{\mathrm{fg}}$ & $0.906 \pm 0.248^{\text {cdef }}$ & $0.977 \pm 0.172 \mathrm{de}$ & $1.013 \pm 0.108 \mathrm{de}$ & $1.789 \pm 0.118^{\text {fgh }}$ & $29.1 \pm 0.605^{\mathrm{d}}$ \\
\hline AT & $0.887 \pm 0.175 \mathrm{abc}$ & $0.6 \pm 0.201$ abcde & $1.487 \pm 0.332$ bcde & $0.076 \pm 0.016^{\mathrm{def}}$ & $0.927 \pm 0.221^{\text {cdef }}$ & $1.008 \pm 0.098$ cde & $1.025 \pm 0.103 \mathrm{de}$ & $2.028 \pm 0.129 \mathrm{de}$ & $31.79 \pm 0.539^{c}$ \\
\hline $\mathrm{AP}$ & $0.875 \pm 0.21 \mathrm{abc}$ & $0.543 \pm 0.137$ bcde & $1.418 \pm 0.325^{\text {cdef }}$ & $0.071 \pm 0.021$ efg & $0.957 \pm 0.198$ bcdef & $1.039 \pm 0.195^{\text {cde }}$ & $1.051 \pm 0.15^{\mathrm{de}}$ & $2.003 \pm 0.148 \mathrm{de}$ & $32.09 \pm 0.617^{b c}$ \\
\hline $\mathrm{TP}$ & $0.426 \pm 0.104^{\text {efg }}$ & $0.505 \pm 0.154^{\text {cdef }}$ & $0.931 \pm 0.254 \mathrm{ij}$ & $0.031 \pm 0.015^{\text {hijk }}$ & $0.888 \pm 0.175^{\text {cdef }}$ & $0.951 \pm 0.185^{\text {def }}$ & $0.904 \pm 0.124$ efg & $1.806 \pm 0.143^{\mathrm{fgh}}$ & $24.2 \pm 0.729^{\mathrm{f}}$ \\
\hline FAT & $1.004 \pm 0.273^{\mathrm{a}}$ & $0.701 \pm 0.156^{a b c}$ & $1.706 \pm 0.39 \mathrm{abc}$ & $0.09 \pm 0.024$ bcde & $1.111 \pm 0.295 \mathrm{abc}$ & $1.303 \pm 0.336^{\mathrm{b}}$ & $1.321 \pm 0.213 b c$ & $2.243 \pm 0.232 \mathrm{bc}$ & $33.03 \pm 0.888^{b}$ \\
\hline FAP & $1.108 \pm 0.168^{\mathrm{a}}$ & $0.777 \pm 0.118^{\mathrm{a}}$ & $1.885 \pm 0.086^{\mathrm{a}}$ & $0.123 \pm 0.027^{\mathrm{a}}$ & $1.313 \pm 0.078^{\mathrm{a}}$ & $1.56 \pm 0.125^{\mathrm{a}}$ & $1.565 \pm 0.196^{\mathrm{a}}$ & $2.531 \pm 0.204^{\mathrm{a}}$ & $35.47 \pm 0.815^{\mathrm{a}}$ \\
\hline FTP & $0.951 \pm 0.226^{\mathrm{ab}}$ & $0.654 \pm 0.118 \mathrm{abcd}$ & $1.605 \pm 0.25 \mathrm{abcd}$ & $0.1 \pm 0.02 \mathrm{abcd}$ & $1.031 \pm 0.234$ bcde & $1.2 \pm 0.224 \mathrm{bcd}$ & $1.175 \pm 0.126^{\mathrm{bcd}}$ & $2.087 \pm 0.19^{\mathrm{cd}}$ & $31.24 \pm 0.859^{c}$ \\
\hline ATP & $0.989 \pm 0.206^{\mathrm{ab}}$ & $0.686 \pm 0.166^{\mathrm{abcd}}$ & $1.675 \pm 0.348 \mathrm{abc}$ & $0.105 \pm 0.025 \mathrm{abc}$ & $1.073 \pm 0.234 \mathrm{abcd}$ & $1.256 \pm 0.203 \mathrm{bc}$ & $1.281 \pm 0.163^{\mathrm{cd}}$ & $2.102 \pm 0.19^{\mathrm{cd}}$ & $31.73 \pm 0.751^{c}$ \\
\hline FATP & $1.006 \pm 0.109^{\mathrm{a}}$ & $0.751 \pm 0.116^{\mathrm{sb}}$ & $1.817 \pm 0.127 \mathrm{ab}$ & $0.113 \pm 0.015 \mathrm{ab}$ & $1.215 \pm 0.256^{\mathrm{ab}}$ & $1.397 \pm 0.316^{\mathrm{ab}}$ & $1.502 \pm 0.209 \mathrm{ab}$ & $2.314 \pm 0.114^{b}$ & $34.95 \pm 0.851^{\mathrm{a}}$ \\
\hline F-ratio & 14.139 & 8.694 & 18.624 & 19.659 & 8.314 & 12.409 & 14.609 & 19.113 & 187.155 \\
\hline Probability & $<0.001$ & $<0.001$ & $<0.001$ & $<0.001$ & $<0.001$ & $<0.001$ & $<0.001$ & $<0.001$ & $<0.001$ \\
\hline
\end{tabular}
$+\mathrm{F} —$ Funelliformis mosseae, A-Acaulospora laevis, T—Trichoderma viride, $\mathrm{P} —$ Pseudomonas fluorescence; \pm -Standard deviation; FW—Fresh Weight, $\ddagger$ values in columns followed by the same
letter are not significantly different, $p \leq 0.05, \mathrm{LSD}$. 
In summary, the best three inoculation treatments among the total sixteen are presented in Table 5. Overall, the treatment with Funelliformis mosseae (F), Acaulospora laevis (A), and Pseudomonas fluorescens (P) was frequently the best treatment for the traits studied.

Table 5. Top three treatments for morphological, floral and biochemical traits studied in Gazania rigens.

\begin{tabular}{|c|c|}
\hline Traits & Treatments * \\
\hline Fresh shoot weight (g) & $\begin{array}{l}\text { FAP } \\
\text { FA } \\
\text { FT }\end{array}$ \\
\hline Dry shoot weight $(\mathrm{g})$ & $\begin{array}{l}\text { FAP } \\
\text { FA } \\
\text { FT }\end{array}$ \\
\hline Fresh root weight $(\mathrm{g})$ & $\begin{array}{l}\text { FAP } \\
\text { FATP } \\
\text { GP } \\
\end{array}$ \\
\hline Dry root weight $(\mathrm{g})$ & $\begin{array}{l}\text { FAP } \\
\text { FATP } \\
\text { GP } \\
\end{array}$ \\
\hline Root length (cm) & $\begin{array}{l}\text { FATP } \\
\text { FAP } \\
\text { FAT }\end{array}$ \\
\hline Number of Leaves & $\begin{array}{l}\text { FATP } \\
\text { FAP } \\
\text { ATP }\end{array}$ \\
\hline Leaf area $\left(\mathrm{cm}^{2}\right)$ & $\begin{array}{l}\text { FAP } \\
\text { FA } \\
\text { GP }\end{array}$ \\
\hline AM spore number & $\begin{array}{l}\text { FAP } \\
\text { FATP } \\
\text { FAT } \\
\end{array}$ \\
\hline AM root colonization (\%) & $\begin{array}{l}\text { FAP } \\
\text { FATP } \\
\text { FAT } \\
\end{array}$ \\
\hline No. of floral heads per plant & $\begin{array}{l}\text { FATP } \\
\text { ATP } \\
\text { FAP }\end{array}$ \\
\hline Peduncle length $(\mathrm{cm})$ & $\begin{array}{l}\text { FAP } \\
\text { AP } \\
\text { FA }\end{array}$ \\
\hline Diameter of flower head $(\mathrm{cm})$ & $\begin{array}{l}\text { FAP } \\
\text { FATP } \\
\text { FAT } \\
\end{array}$ \\
\hline Flower fresh weight $(\mathrm{g})$ & $\begin{array}{l}\text { FAP } \\
\text { FAT } \\
\text { FATP }\end{array}$ \\
\hline Flower dry weight (g) & $\begin{array}{l}\text { FAP } \\
\text { FATP } \\
\text { FAT }\end{array}$ \\
\hline Flower age on the plant (days) & $\begin{array}{l}\text { FAP } \\
\text { FATP } \\
\text { FAT }\end{array}$ \\
\hline Chlorophyll a (mg/g FW) & $\begin{array}{l}\text { FAP } \\
\text { FATP } \\
\text { FAT } \\
\end{array}$ \\
\hline Chlorophyll b (mg/g FW) & $\begin{array}{l}\text { FAP } \\
\text { FATP } \\
\text { FAT } \\
\end{array}$ \\
\hline Total chlorophyll (mg/g FW) & $\begin{array}{l}\text { FAP } \\
\text { FATP } \\
\text { FAT }\end{array}$ \\
\hline
\end{tabular}


Table 5. Cont.

\begin{tabular}{|c|c|}
\hline Traits & Treatments * \\
\hline Total carotenoids (mg/g FW) & $\begin{array}{l}\text { FAP } \\
\text { FATP } \\
\text { ATP }\end{array}$ \\
\hline Shoot Phosphorus Content (\%) & $\begin{array}{l}\text { FAP } \\
\text { FATP } \\
\text { FAT }\end{array}$ \\
\hline Root Phosphorus Content (\%) & $\begin{array}{l}\text { FAP } \\
\text { FATP } \\
\text { FAT }\end{array}$ \\
\hline Acidic Phosphatase (IU g $\left.{ }^{-1} \mathrm{FW}\right)$ & $\begin{array}{l}\text { FAP } \\
\text { FATP } \\
\text { FAT }\end{array}$ \\
\hline Alkaline Phosphatase $\left(\mathrm{IU} \mathrm{g}^{-1} \mathrm{FW}\right)$ & $\begin{array}{l}\text { FAP } \\
\text { FATP } \\
\text { FAT }\end{array}$ \\
\hline Anthocyanin content (mg/100 g FW) & $\begin{array}{l}\text { FAP } \\
\text { FATP } \\
\text { FAT }\end{array}$ \\
\hline
\end{tabular}

\section{Discussion}

Gazania is also known as the treasure flower and originates from South Africa. The flowers of gazania possess a long flower life; therefore, in gardens they are generally used for bedding, edging and as well as for mass planting [52]. The present study demonstrated that bioinoculant-treated plants grew well, and flowering varied with different combinations used. It is clear-cut from the data that bioinoculant-infected plants showed better results in growth and mineral nutrition compared to un-inoculated control plants. The hyphopodia of AMF enter the root cortex to obtain carbon from the host plant and in return assist the plant with more uptake of nutrients, especially $\mathrm{P}$, which is necessary for the synthesis of nucleic acids [53], enhancing vegetative growth [54,55]; this might be the reason for the higher weight (fresh/dry root/shoot weight) of the plants. Along these lines, our study found that the combination of AMF (F. mosseae and A. laevis) with Pseudomonas fluorescence had the best result among the bioinoculants used. Similarly, it is also confirmed that bioinoculated plants of Tagetus patula showed increased leaf area and shoot and root fresh and dry weight [56].

The effectiveness of bioinoculants can differ with inoculant forms, soil properties and environmental conditions [57]. Polyhouse conditions were selected for the experiment and soil samples were autoclaved. Generally, Funelliformis mosseae and Acaulospora laevis have a different magnitude of root colonization because the extent of absorption of water and minerals might differ among treatments [58,59]. If the level of absorbed minerals is different, that could lead to a variation in plant growth parameters we considered in this study [60]. Similarly, Trichoderma viride and Pseudomonas fluorescence possess a different absorption rate [61]. Furthermore, the AMF produce some organo-polysaccharides exudates that are crucial for soil porosity and soil quality [62], whereas, if AMF amalgamates with Trichoderma viride and Pseudomonas fluorescence, the amount and form of these exudates become more commendable [63]. Hyphae of mycorrhizal fungi-infected roots can penetrate deep in the phosphorus depletion zone and make phosphorus easily accessible for plants [64].

PSB can solubilize orthophosphates and AMF roots can easily absorb these orthophosphates. Therefore, in our study, different combinations altered the absorption rate [65]. When the number of absorbed minerals differs, plants have diverse amounts of phytoaccumulation and phytohormones [66]. This change is directly linked to the photosynthetic rate in the plant combinations [67]. Usually, the amount of exudates is linked with the amount of carbon the AMF is receiving from its host [68]. Hence, different combinations of bioinoculants varied in their response, and plants showed an overall diverse characterization. 
The AMF root colonization (\%) and AMF spore number were significantly more developed in the treated plants as compared to the control. Furthermore, the treatments T, P and TP showed no AMF root colonization (\%) because both of the microorganisms ( $\mathrm{T}$ and $\mathrm{P}$ ) belong to the non-infectious group and are mycorrhizal-activating microbes. Trichoderma viride is a mycorrhizal helper fungus; it assists in the colonization of already present AMF but never colonizes on its own. Similarly, Pseudomonas is phosphate-solubilizing bacteria [69]. Moreover, the soil used was autoclaved and the experiment was performed under polyhouse conditions, so there were limited chances of infection.

These results are in line with previous studies carried out on flowering plants [70-72]. Findings of Scagel [73] for yellow zephyr lily are correlated with our work as the inoculated plants showed earlier flowering as compared to the control. This might be due to the enhanced production of auxin and gibberellin that induces bud production due to higher levels of potassium absorption by the plant [74-76]. Similarly, an increased flower number was also recorded for the Tagetes sp., Zinnia sp. and Callistephus sp., with the use of AMF treatment [77-79]. In treatments with bioinoculants plant characters like diameter, fresh and dry weight of flowers were better than those of the un-inoculated plants and this might be due to higher absorption of water and minerals like P, Fe and Zn [80]. In this direction, Vaingankar and Rodrigues [81] showed a similar increase in weight of Crossandra infundibuliformis flowers when AMF treatment was applied. Our results showed the enhancement in total chlorophyll and carotenoid contents in the treated plants, probably due to increased stomatal conductance and photosynthesis [82]. Another reason could be an increase in the number and size of the chloroplasts [83].

In the case of shoot and root $\mathrm{P}$ concentration, a mycorrhizal effect was evident, because the AMF-associated roots produced some acid phosphatases and hydrolase enzymes that increased phosphate availability in the rhizosphere [84,85]. These results correspond with the work of Nowak [86], where Pelargonium hortorum grew under low NPK supply but with mycorrhizal fungi, an increase in the P content was noted. Acid and alkaline phosphatase activities increased in the treatment with AMF in combination with P. fluorescence. This augmentation may be attributed to increased activity of phosphatase enzyme, which results in mineralization of inorganic phosphorus from organic compounds [87]. Previously, a high level of phosphatase activity was reported by using histo/cytochemical staining techniques, proving that AMF increase alkaline phosphatase activity [88-90]. Moreover, it has been suggested that biofertilizers possess great potential for the horticulture industry [91]. Likewise, this study proposes that growers should consider microbial inoculants for the better yield and flower quality of G. rigens.

\section{Conclusions}

Arbuscular mycorrhizal fungi (AMF) benefit host plants symbiotically in many aspects such as the uptake of phosphorus and other nutrients, increased plant growth hormone production, plant height, total leaf area, fresh/dry weight of shoots and roots, number and weight of flowers, the rate of colonization and arbuscular richness and also provide resistance to phytopathogens. Being a semi-arid region, Haryana faces a problem in the large production of the floriculture industry; therefore, the use of AMF may be implemented in nursery practices for improved crop growth and yield. Overall, we have concluded that bioinoculant treatment is promising for G. rigens; furthermore, bioinoculants are eco-friendly and inexpensive compared to chemical fertilizers. This study was carried out under controlled conditions; therefore, it is not known how plants will be affected under natural conditions where climatic factors and microbes have to interact more closely with each other to yield a plant ideotype.

Author Contributions: I.S. and A.A. conceived and designed the project. A.A. supervised the study. I.S. performed the experiments. I.S. and P.K. analyzed the data. I.S., A.A. and P.K. wrote the paper and corrected the final draft. All authors read and approved the final manuscript.

Funding: This research received no external funding. 
Acknowledgments: The authors are thankful to the anonymous reviewers for their careful reading of the manuscript and providing insightful suggestions.

Conflicts of Interest: The authors declare no conflict of interest.

\section{References}

1. Vujošević, A.; Lakić, N.; Beatović, D.; Jelačić, S. Influence of slow disintegrating fertilizer rates on quality of gazania (Gazania rigens L.) seedlings. J. Agric. Sci. 2007, 52, 121-130.

2. Pittenger, D.R.; Shaw, D.A.; Hodel, D.R.; Holt, D.B. Responses of landscape groundcovers to minimum irrigation. J. Environ. Hortic. 2001, 19, 78-84.

3. Howis, S.; Barker, N.P.; Mucina, L. Globally Grown, but Poorly Known: Species Limits and Biogeography of Gazania Gaertn. (Asteraceae) Inferred from Chloroplast and Nuclear DNA Sequence Data. Taxon 2009, 58, 871-882. [CrossRef]

4. Foroutan Nia, A.; Bahman, S.; Naghdi Badi, H.; Mehrafarin, A.; Labbafi, M. Morpho-physiological and phytochemical traits of gazania (Gazania rigens) affected by foliar application of bio-stimulants. EurAsian J. Biosci. 2015, 9. [CrossRef]

5. Moustafa, A.M.Y.; Khodair, A.I. Phytochemical Investigation and a-Cellulose Content Determination of Gazania splendens Moore. Res. J. Phytochem. 2007, 1, 21-32.

6. Kommidi, D.R.; Himakar Reddy, K.; Moodley, B.; Govender, P.; Koorbanally, N. Bio Evaluation of Different Fractions of Gazania rigens. J. Pure Appl. Microbiol. 2014, 8, 2014.

7. Ninama, A.P.; Sipai, S.A.; Khadayata, K.G.; Patel, P.C. Floriculture in India: Problems and Prospect. Advances in Life Sciences 2016, 5, 1150-1153.

8. Talebi, M.; Hadavi, E.; Jaafari, N. Foliar Sprays of Citric Acid and Malic Acid Modify Growth, Flowering, and Root to Shoot Ratio of Gazania (Gazania rigens L.): A Comparative Analysis by ANOVA and Structural Equations Modeling. Available online: https:/ /www.hindawi.com/journals/aag/2014/147278/ (accessed on 2 January 2019).

9. Roy, D.; Thorat, A. Success in high value horticultural export markets for the small farmers: The case of Mahagrapes in India. World Dev. 2008, 36, 1874-1890. [CrossRef]

10. Nehra, V.; Choudhary, M. A review on plant growth promoting rhizobacteria acting as bioinoculants and their biological approach towards the production of sustainable agriculture. J. Appl. Nat. Sci. 2015, 7, 540-556. [CrossRef]

11. Bloemberg, G.V.; Lugtenberg, B.J. Molecular basis of plant growth promotion and biocontrol by rhizobacteria. Curr. Opin. Plant Biol. 2001, 4, 343-350. [CrossRef]

12. Glick, B.R. The enhancement of plant growth by free-living bacteria. Can. J. Microbiol. 1995, 41, $109-117$. [CrossRef]

13. Mishra, P.K.; Joshi, P.; Suyal, P.; Bisht, J.K.; Bhatt, J.C. Potential of phosphate solubilising microorganisms in crop production. In Bioresources for Sustainable Plant Nutrient Management; Satish Serial Publishing House: New Delhi, India, 2014; pp. 201-222.

14. Miransari, M. Soil microbes and the availability of soil nutrients. Acta Physiol. Plant. 2013, 35, 3075-3084. [CrossRef]

15. Weisany, W.; Raei, Y.; Salmasi, S.Z.; Sohrabi, Y.; Ghassemi-Golezani, K. Arbuscular mycorrhizal fungi induced changes in rhizosphere, essential oil and mineral nutrients uptake in dill/common bean intercropping system. Ann. Appl. Biol. 2016, 169, 384-397. [CrossRef]

16. Rashid, M.; Khalil, S.; Ayub, N.; Alam, S.; Latif, F. Organic acids production and phosphate solubilization by phosphate solubilizing microorganisms (PSM) under in vitro conditions. Pak. J. Biol. Sci. 2004, 7, 187-196.

17. Saini, I.; Yadav, K.; Aggarwal, A. Effect of bioinoculants on morphological and biochemical parameters of Zinnia elegans Jacq. J. Appl. Hortic. 2017, 19, 167-172.

18. Richardson, A.E. Prospects for using soil microorganisms to improve the acquisition of phosphorus by plants. Funct. Plant Biol. 2001, 28, 897-906. [CrossRef]

19. Rillig, M.C.; Mummey, D.L. Mycorrhizas and soil structure. New Phytol. 2006, 171, 41-53. [CrossRef]

20. Jones, D.L.; Hodge, A.; Kuzyakov, Y. Plant and mycorrhizal regulation of rhizodeposition. New Phytol. 2004, 163, 459-480. [CrossRef] 
21. Luján Adela, M.; Pedro, G. Buckling Angus Siderophore cooperation of the bacterium Pseudomonas fluorescens in soil. Biol. Lett. 2015, 11, 20140934. [CrossRef]

22. David, B.V.; Chandrasehar, G.; Selvam, P.N. Pseudomonas fluorescens: A Plant-Growth-Promoting Rhizobacterium (PGPR) With Potential Role in Biocontrol of Pests of Crops. In Crop Improvement Through Microbial Biotechnology; Elsevier: Amsterdam, The Netherlands, 2018; pp. 221-243.

23. Bardin, M.; Ajouz, S.; Comby, M.; Lopez-Ferber, M.; Graillot, B.; Siegwart, M.; Nicot, P.C. Is the efficacy of biological control against plant diseases likely to be more durable than that of chemical pesticides? Front. Plant Sci. 2015, 6. [CrossRef]

24. Susilowati, A.; Wahyudi, A.T.; Lestari, Y.; Suwanto, A.; Wiyono, S. Potential Pseudomonas isolated from soybean rhizosphere as biocontrol against soilborne phytopathogenic fungi. Hayati J. Biosci. 2011, 18, 51-56. [CrossRef]

25. Barahona, E.; Navazo, A.; Martínez-Granero, F.; Zea-Bonilla, T.; Pérez-Jiménez, R.M.; Martín, M.; Rivilla, R. Pseudomonas fluorescens F113 Mutant with Enhanced Competitive Colonization Ability and Improved Biocontrol Activity against Fungal Root Pathogens. Appl. Environ. Microbiol. 2011, 77, 5412-5419. [CrossRef] [PubMed]

26. Rohrbacher, F.; St-Arnaud, M. Root exudation: The ecological driver of hydrocarbon rhizoremediation. Agronomy 2016, 6, 19. [CrossRef]

27. Mukherjee, M.; Mukherjee, P.K.; Horwitz, B.A.; Zachow, C.; Berg, G.; Zeilinger, S. Trichoderma-Plant-Pathogen Interactions: Advances in Genetics of Biological Control. Indian J. Microbiol. 2012, 52, 522-529. [CrossRef]

28. Harman, G.E.; Howell, C.R.; Viterbo, A.; Chet, I.; Lorito, M. Trichoderma species-Opportunistic, avirulent plant symbionts. Nat. Rev. Microbiol. 2004, 2, 43-56. [CrossRef]

29. Paul, D.; Lade, H. Plant-growth-promoting rhizobacteria to improve crop growth in saline soils: A review. Agron. Sustain. Dev. 2014, 34, 737-752. [CrossRef]

30. dos Santos, M.L.; Berlitz, D.L.; Wiest, S.L.F.; Schünemann, R.; Knaak, N.; Fiuza, L.M. Benefits Associated with the Interaction of Endophytic Bacteria and Plants. Braz. Arch. Biol. Technol. 2018, 61. [CrossRef]

31. Khan, A.G. Role of soil microbes in the rhizospheres of plants growing on trace metal contaminated soils in phytoremediation. J. Trace Elem. Med. Biol. 2005, 18, 355-364. [CrossRef]

32. Glick, B.R. Plant Growth-Promoting Bacteria: Mechanisms and Applications. Science 2012, 2012. [CrossRef]

33. Pathak, D.V.; Kumar, M.; Rani, K. Biofertilizer Application in Horticultural Crops. In Microorganisms for Green Revolution; Springer: Berlin/Heidelberg, Germany, 2017; pp. 215-227.

34. Adesemoye, A.O.; Torbert, H.A.; Kloepper, J.W. Plant growth-promoting rhizobacteria allow reduced application rates of chemical fertilizers. Microb. Ecol. 2009, 58, 921-929. [CrossRef]

35. Jacoby, R.; Peukert, M.; Succurro, A.; Koprivova, A.; Kopriva, S. The Role of Soil Microorganisms in Plant Mineral Nutrition-Current Knowledge and Future Directions. Front. Plant Sci. 2017, 8. [CrossRef] [PubMed]

36. Kibblewhite, M.; Ritz, K.; Swift, M. Soil health in agricultural systems. Philos. Trans. R. Soc. Lond. B Biol. Sci. 2008, 363, 685-701. [CrossRef] [PubMed]

37. Berruti, A.; Lumini, E.; Balestrini, R.; Bianciotto, V. Arbuscular Mycorrhizal Fungi as Natural Biofertilizers: Let's Benefit from Past Successes. Front. Microbiol. 2015, 6, 1559. [CrossRef] [PubMed]

38. Bona, E.; Lingua, G.; Manassero, P.; Cantamessa, S.; Marsano, F.; Todeschini, V.; Copetta, A.; D'Agostino, G.; Massa, N.; Avidano, L.; et al. AM fungi and PGP pseudomonads increase flowering, fruit production, and vitamin content in strawberry grown at low nitrogen and phosphorus levels. Mycorrhiza 2015, 25, 181-193. [CrossRef] [PubMed]

39. Janowska, B.; Andrzejak, R. Effect of mycorrhizal inoculation on development and flowering of Tagetes patula L.'Yellow Boy'and Salvia splendens Buc'hoz ex Etl.'Saluti Red'. History 2017, 70, 1703.

40. Schenck, N.C.; Pérez, Y. Manual for the identification of VA Mycorrhizal Fungi; Synergistic Publications: Gainesville, FL, USA, 1990; ISBN 978-0-9625980-3-6.

41. Johnson, L.F.; Curl, E.A.; Bond, J.H.; Fribourg, H.A. Methods for Studying Soil Microflora-Plant Disease Relationships; Burgess Pub Co.: Minneapolis, MN, USA, 1960.

42. Leslie, J.F.; Summerell, B.A. The Fusarium Laboratory Manual; Wiley-Blackwell: Hoboken, NJ, USA, 2006.

43. Arnon, D.I. Copper enzymes in isolated chloroplasts. Polyphenoloxidase in Beta vulgaris. Plant Physiol. 1949, 24, 1. [CrossRef] 
44. Tsushida, T. Isolation of flavonoid-glycosides in onion and identification by chemical synthesis of glycosides (Flavonoid in fruits and vegetables Part 1). Nippon Shokuhin Kagaku Kogaku Kaishi 1995, 42, 100-108. [CrossRef]

45. Tabatabai, M.A.; Bremner, J.M. Use of p-nitrophenyl phosphate for assay of soil phosphatase activity. Soil Biol. Biochem. 1969, 1, 301-307. [CrossRef]

46. Jackson, M.L. Vanadomolybdo phosphoric yellow colour method for determination of phosphorus. In Soil Chemical Analysis; Prentice Hall of India Pvt. Ltd.: New Delhi, India, 1973; pp. 151-154.

47. Gerdemann, W.J. Spores of mycorrhizal Endogone species extracted from soil by wet sieving and decanting. Trans. Br. Mycol. Soc. 1963, 46, 235-244. [CrossRef]

48. Sharma, N.; Yadav, K.; Aggarwal, A. Growth Response of Two Phaseolus mungo L. Cultivars Induced by Arbuscular Mycorrhizal Fungi and Trichoderma viride. Available online: https:/ /www.hindawi.com/ journals/ija/2016/1524304/ (accessed on 5 January 2019).

49. Phillips, J.M.; Hayman, D.S. Improved procedures for clearing roots and staining parasitic and vesicular-arbuscular mycorrhizal fungi for rapid assessment of infection. Trans. Br. Mycol. Soc. 1970, 55, 158-161. [CrossRef]

50. Giovannetti, M.; Mosse, B. An Evaluation of Techniques for Measuring Vesicular Arbuscular Mycorrhizal Infection in Roots. New Phytol. 1980, 84, 489-500. [CrossRef]

51. Nie, N.H.; Bent, D.H.; Hull, C.H. SPSS: Statistical Package for the Social Sciences; McGraw-Hill: New York, NY, USA, 1975.

52. Zeng, J.; Wang, D.; Wu, Y.; Guo, X.; Zhang, Y.; Lu, X. Karyotype Analysis of Gazania rigens Varieties. Hortic. Plant J. 2016, 2, 279-283. [CrossRef]

53. Zubillaga, M.M.; Aristi, J.P.; Lavado, R.S. Effect of phosphorus and nitrogen fertilization on sunflower (Helianthus annus L.) nitrogen uptake and yield. J. Agron. Crop Sci. 2002, 188, 267-274. [CrossRef]

54. Bona, E.; Cantamessa, S.; Massa, N.; Manassero, P.; Marsano, F.; Copetta, A.; Lingua, G.; D’Agostino, G.; Gamalero, E.; Berta, G. Arbuscular mycorrhizal fungi and plant growth-promoting pseudomonads improve yield, quality and nutritional value of tomato: A field study. Mycorrhiza 2017, 27, 1-11. [CrossRef] [PubMed]

55. Baum, C.; El-Tohamy, W.; Gruda, N. Increasing the productivity and product quality of vegetable crops using arbuscular mycorrhizal fungi: A review. Sci. Hortic. 2015, 187, 131-141. [CrossRef]

56. Schmidt, B.; Domonkos, M.; Sumalan, R.; Biró, B. Suppression of arbuscular mycorrhiza's development by high concentration of phosphorus at Tagetes patula L. Res. J. Agric. Sci. 2010, 42, 156-162.

57. Lesueur, D.; Deaker, R.; Herrmann, L.; Bräu, L.; Jansa, J. The production and potential of biofertilizers to improve crop yields. In Bioformulations: For sustainable Agriculture; Springer: Berlin/Heidelberg, Germany, 2016; pp. 71-92.

58. Fiscus, E.L.; Markhart, A.H. Relationships between Root System Water Transport Properties and Plant Size in Phaseolus1. Plant Physiol. 1979, 64, 770-773. [CrossRef] [PubMed]

59. Wang, M.; Jiang, P. Colonization and Diversity of AM Fungi by Morphological Analysis on Medicinal Plants in Southeast China. Sci. World J. 2015, 2015. [CrossRef]

60. Fageria, N.K.; Moreira, A. The role of mineral nutrition on root growth of crop plants. In Advances in Agronomy; Elsevier: Amsterdam, The Netherlands, 2011; Volume 110, pp. 251-331.

61. Shanmugaiah, V.; Balasubramanian, N.; Gomathinayagam, S.; Manoharan, P.T.; Rajendran, A. Effect of single application of Trichoderma viride and Pseudomonas fluorescens on growth promotion in cotton plants. Afr. J. Agric. Res. 2009, 4, 1220-1225.

62. Rashid, M.I.; Mujawar, L.H.; Shahzad, T.; Almeelbi, T.; Ismail, I.M.; Oves, M. Bacteria and fungi can contribute to nutrients bioavailability and aggregate formation in degraded soils. Microbiol. Res. 2016, 183, $26-41$. [CrossRef]

63. Saeedizadeh, A. Trichoderma viride and Pseudomonas fluorescens CHA0 against Meloidogyne javanica in the rhizosphere of tomato plants. Hell. Plant Prot. J. 2016, 9, 28-34. [CrossRef]

64. Bücking, H.; Liepold, E.; Ambilwade, P. The Role of the Mycorrhizal Symbiosis in Nutrient Uptake of Plants and the Regulatory Mechanisms Underlying These Transport Processes. Plant Sci. 2012. [CrossRef]

65. Johri, A.K.; Oelmüller, R.; Dua, M.; Yadav, V.; Kumar, M.; Tuteja, N.; Varma, A.; Bonfante, P.; Persson, B.L.; Stroud, R.M. Fungal association and utilization of phosphate by plants: Success, limitations, and future prospects. Front. Microbiol. 2015, 6. [CrossRef] [PubMed]

66. Park, J.; Lee, Y.; Martinoia, E.; Geisler, M. Plant hormone transporters: What we know and what we would like to know. BMC Biol. 2017, 15. [CrossRef] [PubMed] 
67. Johnson, M.P. Photosynthesis. Essays Biochem. 2016, 60, 255-273. [CrossRef] [PubMed]

68. Gorzelak, M.A.; Asay, A.K.; Pickles, B.J.; Simard, S.W. Inter-plant communication through mycorrhizal networks mediates complex adaptive behaviour in plant communities. AoB Plants 2015, 7. [CrossRef] [PubMed]

69. Vázquez, M.M.; César, S.; Azcón, R.; Barea, J.M. Interactions between arbuscular mycorrhizal fungi and other microbial inoculants (Azospirillum, Pseudomonas, Trichoderma) and their effects on microbial population and enzyme activities in the rhizosphere of maize plants. Appl. Soil Ecol. 2000, 15, 261-272. [CrossRef]

70. Kil, Y.-J.; Eo, J.-K.; Lee, E.-H.; Eom, A.-H. Root Age-Dependent Changes in Arbuscular Mycorrhizal Fungal Communities Colonizing Roots of Panax ginseng. Mycobiology 2014, 42, 416-421. [CrossRef]

71. Moreira, M.; Baretta, D.; Tsai, S.M.; Cardoso, E.J.B.N. Spore density and root colonization by arbuscular mycorrhizal fungi in preserved or disturbed Araucaria angustifolia (Bert.) O. Ktze. ecosystems. Sci. Agric. 2006, 63, 380-385. [CrossRef]

72. Retama-Ortiz, Y.; Ávila-Bello, C.H.; Alarcón, A.; Ferrera-Cerrato, R. Effectiveness of native arbuscular mycorrhiza on the growth of four tree forest species from the Santa Marta Mountain, Veracruz (Mexico). For. Syst. 2017, 26, 1. [CrossRef]

73. Scagel, C.F. Soil pasteurization and inoculation with Glomus intraradices alters flower production and bulb composition of Zephyranthes spp. J. Hortic. Sci. Biotechnol. 2003, 78, 798-812. [CrossRef]

74. Krizek, B.A.; Fletcher, J.C. Molecular mechanisms of flower development: An armchair guide. Nat. Rev. Genet. 2005, 6, 688-698. [CrossRef] [PubMed]

75. Alvarez-Buylla, E.R.; Benítez, M.; Corvera-Poiré, A.; Chaos Cador, A.; de Folter, S.; Gamboa de Buen, A.; Garay-Arroyo, A.; García-Ponce, B.; Jaimes-Miranda, F.; Pérez-Ruiz, R.V.; et al. Flower development. Arab. Book 2010, 8, e0127. [CrossRef] [PubMed]

76. Asmelash, F.; Bekele, T.; Birhane, E. The Potential Role of Arbuscular Mycorrhizal Fungi in the Restoration of Degraded Lands. Front. Microbiol. 2016, 7. [CrossRef] [PubMed]

77. Osborne, O.G.; De-Kayne, R.; Bidartondo, M.I.; Hutton, I.; Baker, W.J.; Turnbull, C.G.N.; Savolainen, V. Arbuscular mycorrhizal fungi promote coexistence and niche divergence of sympatric palm species on a remote oceanic island. New Phytol. 2018, 217, 1254-1266. [CrossRef]

78. Aboul-Nasr, A. Effects of vesicular-arbuscular mycorrhiza on Tagetes erecta and Zinnia elegans. Mycorrhiza 1995, 6, 61-64. [CrossRef]

79. Gaur, A.; Adholeya, A. Diverse Response of Five Ornamental Plant Species to Mixed Indigenous and Single Isolate Arbuscular-Mycorrhizal Inocula in Marginal Soil Amended with Organic Matter. J. Plant Nutr. 2005, 28, 707-723. [CrossRef]

80. Miransari, M.; Bahrami, H.A.; Rejali, F.; Malakouti, M.J. Effects of arbuscular mycorrhiza, soil sterilization, and soil compaction on wheat (Triticum aestivum L.) nutrients uptake. Soil Tillage Res. 2009, 104, 48-55. [CrossRef]

81. Vaingankar, J.D.; Rodrigues, B.F. Effect of Arbuscular Mycorrhizal (AM) Inoculation on Growth and Flowering in Crossandra infundibuliformis (L.) Nees. J. Plant Nutr. 2015, 38, 1478-1488. [CrossRef]

82. Boldt, K.; Pörs, Y.; Haupt, B.; Bitterlich, M.; Kühn, C.; Grimm, B.; Franken, P. Photochemical processes, carbon assimilation and RNA accumulation of sucrose transporter genes in tomato arbuscular mycorrhiza. J. Plant Physiol. 2011, 168, 1256-1263. [CrossRef]

83. Arumugam, R.; Rajasekaran, S.; Nagarajan, S.M. Response of Arbuscular mycorrhizal fungi and Rhizobium inoculation on growth and chlorophyll content of Vigna unguiculata (L.) Walp Var. Pusa 151. J. Appl. Sci. Environ. Manag. 2010, 14. [CrossRef]

84. Miller, S.S.; Liu, J.; Allan, D.L.; Menzhuber, C.J.; Fedorova, M.; Vance, C.P. Molecular Control of Acid Phosphatase Secretion into the Rhizosphere of Proteoid Roots from Phosphorus-Stressed White Lupin. Plant Physiol. 2001, 127, 594-606. [CrossRef] [PubMed]

85. Renella, G.; Egamberdiyeva, D.; Landi, L.; Mench, M.; Nannipieri, P. Microbial activity and hydrolase activities during decomposition of root exudates released by an artificial root surface in Cd-contaminated soils. Soil Biol. Biochem. 2006, 38, 702-708. [CrossRef]

86. Nowak, J. Effects of Arbuscular Mycorrhizal Fungi and Organic Fertilization on Growth, Flowering, Nutrient Uptake, Photosynthesis and Transpiration of Geranium (Pelargonium hortorum L.H. Bailey 'Tango Orange'). Symbiosis. 2004. Available online: http:/ / agris.fao.org/agris-search/search.do?recordID=US201301021943 (accessed on 3 February 2019 ). 
87. Amaya-Carpio, L.; Davies, F.T.; Fox, T.; He, C. Arbuscular mycorrhizal fungi and organic fertilizer influence photosynthesis, root phosphatase activity, nutrition, and growth of Ipomoea carnea ssp. fistulosa. Photosynthetica 2009, 47, 1-10. [CrossRef]

88. Tisserant, B.; Gianinazzi-Pearson, V.; Gianinazzi, S.; Gollotte, A. In planta histochemical staining of fungal alkaline phosphatase activity for analysis of efficient arbuscular mycorrhizal infections. Mycol. Res. 1993, 97, 245-250. [CrossRef]

89. MacDonald, R.M.; Lewis, M. The occurance of some acid phosphates and dehydrogenases in the vesicular-arbuscular mycorrhizal fungus Glomus mosseae. New Phytol. 1978, 80, 135-141. [CrossRef]

90. Saito, M. Enzyme activities of the internal hyphae and germinated spores of an arbuscular mycorrhizal fungus, Gigaspora margarita Becker \& Hall. New Phytol. 1995, 129, 425-431. [CrossRef]

91. Bianciotto, V.; Victorino, I.; Scariot, V.; Berruti, A. Arbuscular mycorrhizal fungi as natural biofertilizers: Current role and potential for the horticulture industry. Acta Hortic. 2018, 207-216. [CrossRef]

C 2019 by the authors. Licensee MDPI, Basel, Switzerland. This article is an open access article distributed under the terms and conditions of the Creative Commons Attribution (CC BY) license (http://creativecommons.org/licenses/by/4.0/). 